EXTENDED REPORT

\title{
Effect of retrobulbar versus subconjunctival anaesthesia on retrobulbar haemodynamics
}

\author{
K K Huber, A Remky
}

Br J Ophthalmol 2005;89:719-723. doi: 10.1136/bjo.2004.047282

See end of article for
authors' affiliations
.....................
Correspondence to:
Dr med K K Huber,
Augenklinik
Universitätsklinikum
Aachen, Pauwelsstrasse
30, D-52057 Aachen,
Germany;
khuber@ukaachen.de
Accepted for publication
3 May 2004
.......................

\begin{abstract}
Aim: To investigate the effect of retrobulbar and subconjunctival anaesthesia on retrobulbar haemodynamics by colour Doppler imaging.

Method: 39 patients (mean age 71 (SD 9) years; 19 females, 20 males) undergoing planned cataract surgery were included in the prospective study. Colour Doppler imaging (Siemens Sonoline Sienna, Germany) was performed before, directly after either subconjunctival (16 patients) or retrobulbar (23 patients) anaesthesia, and after cataract surgery to measure the peak systolic (PSV) and end diastolic velocities (EDV) in the ophthalmic artery (OA), central retinal artery (CRA), and central retinal vein (CRV). Results: After retrobulbar anaesthesia there was a significant reduction of the PSV and of the EDV in all investigated vessels. After surgery the flow velocities increased again. Subconjunctival anaesthesia had no significant effects on retrobulbar haemodynamics.

Conclusion: Retrobulbar anaesthesia induces a high reduction of velocity in the retrobulbar vessels in contrast with subconjunctival anaesthesia. Therefore subconjunctival anaesthesia should be preferred particularly in patients with problems of the ocular perfusion (for example, glaucoma).
\end{abstract}

$\mathrm{D}$ ifferent types of techniques of anaesthesia for cataract surgery are common. In the 1980s retrobulbar anaesthesia was the most common form used for anaesthesia. ${ }^{1}$ Recent results from questionnaires demonstrated that retrobulbar anaesthesia is performed in $23 \%$ and peribulbar anaesthesia in $19 \%$ of cases. Less invasive techniques such as sub-Tenon $(2 \%)$ or topical anaesthesia (56\%) are gaining popularity. ${ }^{2}$

Complications of retrobulbar anaesthetics are, beside penetration of the needle in the globe, ischaemic optic neuropathy, ${ }^{3-5}$ occlusion of the central retinal artery, ${ }^{6}$ and retinal, ${ }^{7}$ or outer retinal ischaemic infarction. ${ }^{8}$ This implies that there is a vascular change after local anaesthesia and the complication risk differs by local anaesthetic technique and drug supplement, and vascular risk factors of the patients.

Previous studies with different techniques assessed the influence of retrobulbar anaesthesia on haemodynamic changes. The pulsatile ocular blood flow showed a marked decrease after retrobulbar anaesthesia. ${ }^{9}$ The recovery of the pulsatile ocular blood flow after retrobulbar anaesthesia was very slow. ${ }^{10}$ Recent examinations by colour Doppler imaging in monkeys showed that retrobulbar anaesthesia with lidocaine and adrenaline (epinephrine) significantly reduced the retrobulbar haemodynamics in the central retinal artery and the posterior ciliary arteries. ${ }^{11}$

Colour Doppler imaging (CDI) is a non-invasive ultrasound technique that combines b-scan grey scale imaging of the tissue structure, coloured representation of blood flow based on Doppler shifted frequencies, and pulsed Doppler measurement of blood flow velocities. CDI can give data on flow velocities of retrobulbar blood vessels and vascular downstream resistance. A variety of occlusive diseases of the eye and the orbit have been examined by CDI. CDI is also used for a wide range of other diseases of the eye in which vascular aetiology has been implicated-for example, glaucoma. ${ }^{12-16}$

In this study colour Doppler imaging was performed to quantify the effect of retrobulbar and subconjunctival anaesthesia on retrobulbar haemodynamics. Patients were recruited prospectively and, randomly, either retrobulbar or subconjunctival anaesthesia was applied.

\section{PATIENTS AND METHODS Patients}

In this prospective study 39 patients planned for cataract surgery (small incision, phacoemulsification with intraocular lens (IOL) implantation) were recruited. Exclusion criteria were the presence of systemic diseases affecting ocular circulation-for example, hypertension or diabetes. Furthermore, patients with vascular occlusion in the studied or in the second eye were excluded. The patients with systemic intake of vasoactive medication-for example, aspirin, were also excluded.

Twenty three patients (mean age 71 (SD 8) years; 14 males, nine females) underwent retrobulbar anaesthesia with $2 \mathrm{ml}$ of lidocaine 2\% (Xylocaine) and adrenaline (1:200 000). The other 16 patients (age 75 (9), five males, 13 females) had subconjunctival anaesthesia with $2 \mathrm{ml}$ of lidocaine $2 \%$ and adrenaline (1:200 000). The data of both groups are shown in table 1 .

Informed consent was obtained from each subject including detailed explanation of all procedures before participation in the study. The tenets of the Helsinki declaration were followed throughout the study.

\section{Method}

Measurements of the retrobulbar velocities were performed using a colour Doppler imaging device (Siemens Sonoline Sienna, Germany) in a standardised manner. ${ }^{17}$ For the scan the patient was lying in a supine position with eyes closed and gaze directed towards the ceiling. The examiner's hand rested upon the orbital margin to minimise the pressure on the globe when the $7.5 \mathrm{MHz}$ linear phased array transducer was applied with contact jelly on the upper eyelid. All examinations were performed by one experienced examiner (KH). To perform the measurements of the ophthalmic artery, the central retinal artery, and the central retinal vein a

Abbreviations: CDI, colour Doppler imaging; CRA, central retinal artery; CRV, central retinal vein; EDV, end diastolic velocity; IOL, intraocular lens; OA, ophthalmic artery; PSV, peak systolic velocity; RI, resistive index 


\begin{tabular}{|c|c|c|c|}
\hline & $\begin{array}{l}\text { Retrobulbar } \\
\text { anaesthesia }\end{array}$ & $\begin{array}{l}\text { Subconjunctival } \\
\text { anaesthesia }\end{array}$ & $p$ Values \\
\hline No of patients & 23 & 16 & \\
\hline Mean age (years) & $71(8)$ & $72(9)$ & 0.9 \\
\hline Sex (male/female) & $14 / 9$ & $6 / 10$ & 0.34 \\
\hline $\begin{array}{l}\text { Systolic blood pressure } \\
\text { before operation }(\mathrm{mm} \mathrm{Hg})\end{array}$ & $175(27)$ & $167(33)$ & 0.40 \\
\hline $\begin{array}{l}\text { Diastolic blood pressure } \\
\text { before operation }(\mathrm{mm} \mathrm{Hg})\end{array}$ & 87 (11) & $85(9)$ & 0.53 \\
\hline $\begin{array}{l}\text { Mean arterial pressure } \\
\text { before operation }(\mathrm{mm} \mathrm{Hg})\end{array}$ & $122(16)$ & $114(12)$ & 0.081 \\
\hline Heart rate before operation & $73(11)$ & $74(11)$ & 0.60 \\
\hline Visual acuity in logMAR & 0.81 & 0.97 & 0.63 \\
\hline Corresponding metric value & 0.154 & 0.167 & \\
\hline Intraocular pressure $(\mathrm{mm} \mathrm{Hg})$ & $16.3(4.2)$ & $16.9(7.6)$ & 0.73 \\
\hline
\end{tabular}

0.2 by $0.2 \mathrm{~mm}$ Doppler sample window was used. Peak systolic velocities (PSV) and end diastolic velocities (EDV) were obtained from the velocity waveforms of each artery. The resistive index (RI), known as Pourcelot's ratio, was calculated by the formula (PSV EDV)/(PSV) to characterise peripheral vascular resistive of the vessels studied. ${ }^{17}$

In this study colour Doppler imaging was used before and exactly after anaesthesia was given and after cataract surgery was completed. No ocular compression was performed after the anaesthesia was given. Furthermore, the cardiovascular parameters systolic and diastolic blood pressure and heart rate were measured simultaneously.

Cataract surgery was performed by one surgeon (AR) with a close to cornea $2.8 \mathrm{~mm}$ incision and phacoemulsification with implantation of a hydrophobic foldable intraocular lens (Acrysof, Alcon, Fort Worth, TX, USA).

\section{Statistical analysis}

The statistical analysis was performed using analysis of variance (ANOVA) as computed with Statview (SAS Institute Inc, Cary, NC, USA). A repeated measures ANOVA was used for testing the interaction of the type of anaesthesia.

For post hoc testing, calculations with Fisher's protected least significant difference were carried out. Findings of probability of a type error less than 0.05 were considered to be statistically significant. For the comparison of discrete variables, a $\chi^{2}$ test was calculated for each contingency table.

\section{RESULTS}

After retrobulbar anaesthesia there was a significant reduction of the PSV and EDV for all measured vessels. For the ophthalmic artery the PSV was lowered by $43 \%(p<0.0001)$

Table 2 Means (SD) of flow velocities colour $(\mathrm{cm} / \mathrm{s}$ ) assessed by colour Doppler imaging in patients undergoing cataract surgery with retrobulbar anaesthesia

\begin{tabular}{llll}
\hline & $\begin{array}{l}\text { Before surgery } \\
\text { (baseline) }\end{array}$ & $\begin{array}{l}\text { After retrobulbar } \\
\text { anaesthesia }\end{array}$ & After surgery \\
\hline OA PSV $(\mathrm{cm} / \mathrm{s})$ & $31.83(7.41)$ & $18.09(5.27)^{*}$ & $24.5196 .37)^{* *}$ \\
OA EDV (cm/s) & $6.36(2.28)$ & $3.84(1.59)^{*}$ & $6.2(2.52)^{* *}$ \\
OA RI & $0.80(0.05)$ & $0.79(0.05)^{*}$ & $0.75(0.06)$ \\
CRA PSV (cm/s) & $11.61(1.34)$ & $7.36(1.74)^{*}$ & $9.31(1.6)^{* *}$ \\
CRA EDV (cm/s) & $3.00(0.82)$ & $2.14(0.59)^{*}$ & $2.50(0.56)^{* *}$ \\
CRA RI & $0.74(0.06)$ & $0.71(0.06)$ & $0.73(0.06)$ \\
CRV PSV (cm/s) & $4.95(0.95)$ & $3.34(1.06)^{*}$ & $4.04(1.05)^{* *}$ \\
CRV EDV (cm/s) & $2.74(0.72)$ & $1.94(0.65)^{*}$ & $2.27(0.64)^{* *}$ \\
\hline
\end{tabular}

OA, ophthalmic artery; PSV, peak systolic velocity; EDV, end diastolic velocity; Rl, resistive index; CRA, central retinal artery.

${ }^{*} p<0.001$ to baseline; ${ }^{* *} p<0.001$ to after anaesthesia.

Table 3 Means (SD) of flow velocities $(\mathrm{cm} / \mathrm{s}$ ) assessed by colour Doppler imaging in patients undergoing cataract surgery with subconjunctival anaesthesia

\begin{tabular}{llll}
\hline & $\begin{array}{l}\text { Before surgery } \\
\text { (baseline) }\end{array}$ & $\begin{array}{l}\text { After subconjunctival } \\
\text { anaesthesia }\end{array}$ & After surgery \\
\hline OA PSV (cm/s) & $28.94(6.78)$ & $28.17(6.91)^{*}$ & $28.14(7.09)^{* *}$ \\
OA EDV (cm/s) & $5.98(2.16)$ & $5.90(2.39)^{*}$ & $6.38(2.55)^{* *}$ \\
OA RI & $0.79(0.06)$ & $0.80(0.05)$ & $0.78(0.06)$ \\
CRA PSV (cm/s) & $9.23(1.63)$ & $9.2(1.53)^{*}$ & $9.34(1.46)^{* *}$ \\
CRA EDV (cm/s) & $2.81(0.71)$ & $2.56(0.28)^{*}$ & $2.74(0.51)^{* *}$ \\
CRA RI & $0.70(0.06)$ & $0.72(0.04)$ & $0.71(0.05)$ \\
CRV PSV (cm/s) & $4.58(0.78)$ & $4.56(0.88)^{*}$ & $4.65(0.95)^{* *}$ \\
CRV EDV (cm/s) & $2.45(0.51)$ & $2.52(0.53)^{*}$ & $2.53(0.51)^{* *}$ \\
\hline OA, ophthalmic artery; PSV, peak systolic velocity; EDV, end diastolic velocity; RI, resistive index; CRA, central \\
retinal artery.
\end{tabular}



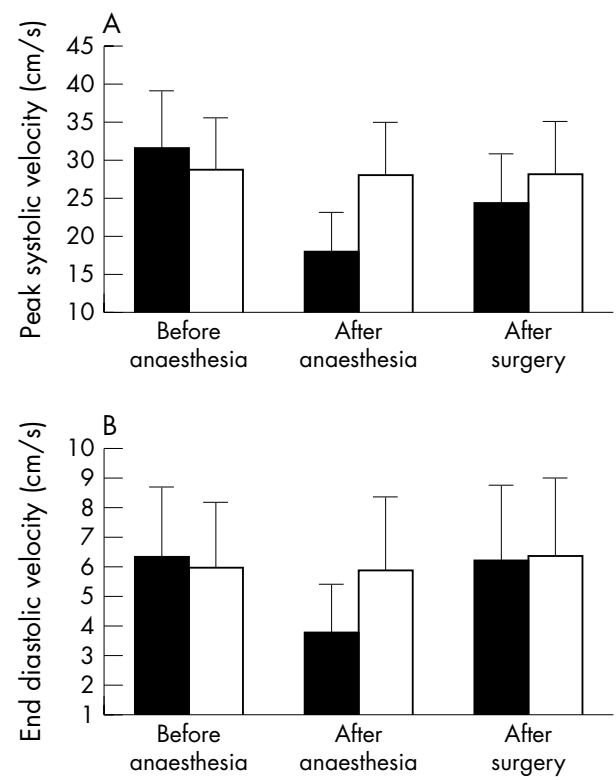

Figure 1 (A) Peak systolic velocity (PSV) and (B) end diastolic velocity (EDV) of the ophthalmic artery (OA) after retrobulbar anaesthesia (solid column) and after subconjunctival anaesthesia (open column).

and the EDV was reduced by $40 \%(\mathrm{p}<0.0001)$. The PSV of the central retinal artery decreased by $32 \%(\mathrm{p}<0.0001)$ and the EDV by $29 \%(\mathrm{p}<0.0001)$. In the central retinal vein there was a reduction of the PSV by $32 \%(\mathrm{p}<0.0001)$ and of the EDV by $29 \% \quad(p<0.0001)$. After surgery flow velocities increased again. In the ophthalmic artery the PSV was raised by $26 \%$ $(p<0.0001)$ and the EDV by $38 \%(p<0.0001)$. In the central retinal artery the velocities increased again-PSV by $21 \%$ and EDV by $15 \%(p<0.0001)$. The PSV of the central retinal vein increased by $17 \% \quad(\mathrm{p}<0.0001)$ and the EDV by $14 \%$ $(\mathrm{p}<0.0001)$.

The resistive index in all vessels showed no significant changes after retrobulbar anaesthesia and directly after surgery. Exact means and standard deviations of the colour Doppler imaging $(\mathrm{cm} / \mathrm{s})$ results of these patients are presented in table 2 .

Subconjunctival anaesthesia had no significant effect on flow velocities of the ophthalmic artery, the central retinal artery, and vein. There was no change in the PSV, EDV, or RI in all studied vessels after subconjunctival anaesthesia or after the completed surgery. Exact means and standard deviations of the colour Doppler imaging $(\mathrm{cm} / \mathrm{s})$ results of these patients are presented in table 3 .

Between both types of anaesthesia there was a highly significant difference in retrobulbar haemodynamics in all studied vessels (OA: PSV $\mathrm{p}<0.001$; EDV $\mathrm{p}<0.001$; CRA: PSV $\mathrm{p}<0.001$; EDV $\mathrm{p} \leqslant 0.0276$; CRV: PSV $\mathrm{p}<0.001$; EDV $\mathrm{p}<0.001$ ). PSV and EDV of all studied vessels, before and directly after anaesthesia and after completed cataract surgery, are shown in figures $1-3$.

Cardiovascular parameters in both groups were significantly different before and after surgery for the systolic $(\mathrm{p}<0.0001)$ and diastolic blood pressure $(\mathrm{p}<0.0113)$. The mean arterial blood pressure $(\mathrm{p}<0.05)$ and the heart rate $(p<0.001)$ also differed significantly before and after surgery (tables 4 and 5). The patients treated with retrobulbar anaesthesia showed no difference in the cardiovascular parameters compared to those treated with subconjunctival anaesthesia.
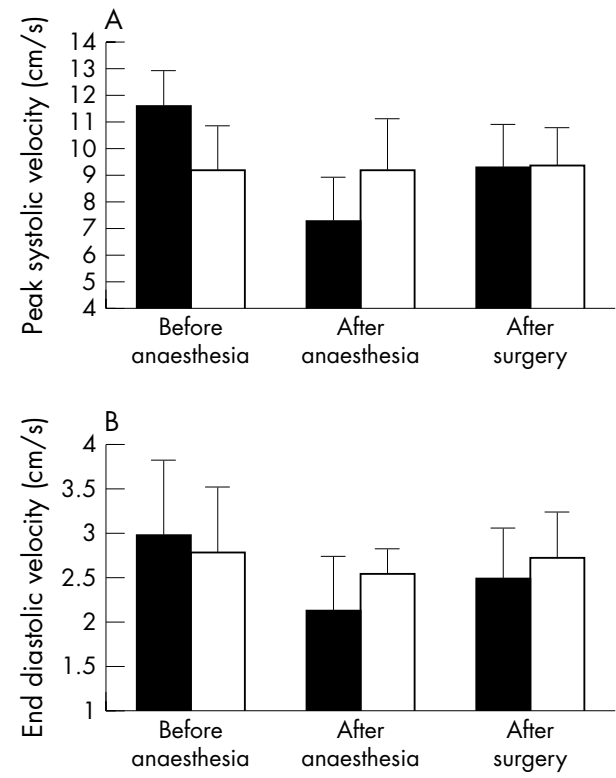

Figure 2 (A) Peak systolic velocity (PSV) and (B) end diastolic velocity (EDV) of the central retina artery (CRA) after retrobulbar anaesthesia (solid column) and after subconjunctival anaesthesia (open column).

\section{DISCUSSION}

In this study we found a tremendous reduction of retrobulbar blood flow velocities after retrobulbar anaesthesia but no changes after subconjunctival anaesthesia.

Subconjunctival anaesthesia is a safe and effective alternative to retrobulbar anaesthesia in cataract surgery ${ }^{18}$ and phacotrabeculectomy. ${ }^{19}$ Even in cyclophotocoagulation it is an alternative anaesthesia and most patients experienced no pain during this procedure. ${ }^{20}$ In addition, cataract surgery with subconjunctival anaesthesia required fewer anaesthetic drugs and there were fewer intraoperative and postoperative complications. ${ }^{18}$
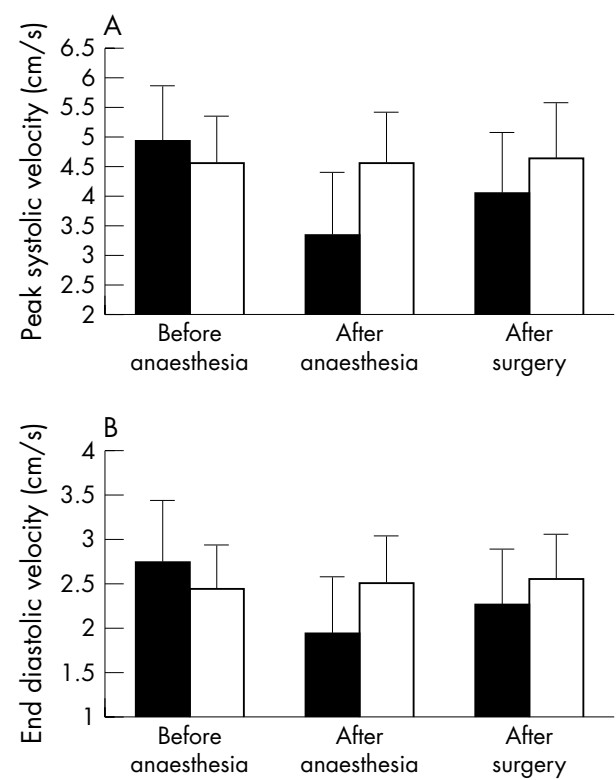

Figure 3 (A) Peak systolic velocity (PSV) and (B) end diastolic velocity (EDV) of the central retina vein (CRV) after retrobulbar anaesthesia (solid column) and after subconjunctival anaesthesia (open column). 
Table 4 Mean (SD) blood pressure $(\mathrm{mm} \mathrm{Hg})$ and pulse in patients undergoing cataract surgery with retrobulbar anaesthesia

\begin{tabular}{llll}
\hline & $\begin{array}{l}\text { Before surgery } \\
\text { (baseline) }\end{array}$ & $\begin{array}{l}\text { After retrobulbar } \\
\text { anaesthesia }\end{array}$ & After surgery \\
\hline Systolic blood pressure & $175(27)$ & $169(27)$ & $162(23)^{*}$ \\
Diastolic blood pressure & $87(11)$ & $86(15)$ & $84(11)^{*}$ \\
Mean arterial pressure & $123(16)$ & $123(25)$ & $117\left(15^{*}\right.$ \\
Heart rate & $73(11)$ & $74(12)$ & $71(17)^{*}$ \\
\hline${ }^{*} \mathrm{p}<0.05$ to baseline. & & & \\
\hline
\end{tabular}

Table 5 Mean (SD) blood pressure $(\mathrm{mm} \mathrm{Hg})$ and pulse in patients undergoing cataract surgery with subconjunctival anaesthesia

\begin{tabular}{llll}
\hline & $\begin{array}{l}\text { Before surgery } \\
\text { (baseline) }\end{array}$ & $\begin{array}{l}\text { After subconjunctival } \\
\text { anaesthesia }\end{array}$ & After surgery \\
\hline Systolic blood pressure & $167(33)$ & $165(30)$ & $157(21)^{*}$ \\
Diastolic blood pressure & $85(9)$ & $84(12)$ & $81(10)^{*}$ \\
Mean arterial pressure & $114(12)$ & $116(19)$ & $110(12)^{*}$ \\
Heart rate & $75(11)$ & $71(11)$ & $70(11)^{*}$ \\
\hline${ }^{*} \mathrm{p}<0.05$ to baseline. & & & \\
\hline
\end{tabular}

Our study showed in all studied vessels a highly significant difference in retrobulbar haemodynamics after retrobulbar or subconjunctival anaesthesia. In contrast to retrobulbar anaesthesia subconjunctival anaesthesia had no significant effects on retrobulbar haemodynamics. These findings are confirmed by the study of Chang et al, ${ }^{21}$ reporting no changes of pulsatile ocular blood flow after subconjunctival local anaesthesia but a significant reduction after peribulbar anaesthesia.

The significant reduction of retrobulbar haemodynamics after retrobulbar anaesthesia recovered only slowly and was still present after surgery. These findings confirm previous reports on the influence of retrobulbar anaesthesia on ocular blood flow. Hubert et al reported a marked decrease of the pulsatile ocular blood flow after retrobulbar anaesthesia. Also the recovery of the pulsatile ocular blood flow was very slowly after retrobulbar anaesthesia. ${ }^{11}$

Several factors may account for the dramatic reduction of velocity after retrobulbar anaesthesia. Firstly, there is a mechanical compression of the retrobulbar tissue space, as a volume effect. This may initiate the decrease in retinal perfusion. Previously, a reduction of the systolic retinal and ciliary perfusion pressures were found after an injection of $5 \mathrm{ml}$ but not after an injection of $2 \mathrm{ml}^{22}$ In this study we found a reduction of retrobulbar velocity after an injection volume of $2 \mathrm{ml}$.

Secondly, it is known that retrobulbar anaesthesia induces a rise in intraocular pressure by $3-4 \mathrm{~mm} \mathrm{Hg} .{ }^{22}{ }^{23}$ The effect of the intraocular pressure rise after retrobulbar anaesthesia lasts only for a short time. ${ }^{22}$ Hessemer et $a l^{22}$ showed that the retinal and ciliary perfusion pressures remained decreased although the IOP had already returned to baseline.

Thirdly, the autoregulation of the retinal circulation may be affected by local anaesthesia. Meyer et al ${ }^{24}$ demonstrated that porcine ciliary arteries are prevented from relaxation by bradykinin in the presence of amide-type anaesthetic agents like lidocaine. This may be a possible explanation for the sustained decrease of ocular blood flow. The diffusion of local anaesthetic into the retrobulbar vessels is proved by the detection of local anaesthetic agent in the peripheral blood. ${ }^{25}$

The three possibilities mentioned above for the reduction in the velocity after retrobulbar anaesthesia do not fit for subconjunctival anaesthesia. Firstly, there is no compression of the retrobulbar vessels because of the location of the anaesthetic. Secondly, there are no IOP changes after subconjunctival anaesthesia. ${ }^{21}$ Thirdly, the diffusion of local anaesthetic into retrobulbar vessels might be very low, because blood levels of lidocaine were negligible. ${ }^{26}$ Netland et $a l^{12}$ was able to show that topical adrenaline can penetrate but has little to no effect on retrobulbar circulation. Therefore, the diffusion of the local anaesthetic might be too slow, or the retrobulbar amount of drug might be too little to show any retrobulbar haemodynamic changes.

In summary, there is a reduction of the retrobulbar velocity after retrobulbar anaesthesia most probably because of a drug induced vasoconstrictive effect of the local anaesthetics. In contrast, there is no reduction of velocity in the retrobulbar vessels after subconjunctival anaesthesia. Although eye motility may be higher in subconjunctival or topical anaesthesia it should be preferred particularly in patients with disturbed ocular haemodynamics (for example, glaucoma, diabetes mellitus).

\section{Authors' affiliations}

K K Huber, A Remky, Department of Ophthalmology, University Hospital Aachen, Medical Faculty of Aachen University, Germany

\section{REFERENCES}

1 Leaming DV. Practice styles and preferences of ASCRS members-1986 survey. J Cataract Refract Surg 1987;13:561-7.

2 David V, Leaming DV. Practice styles and preferences of ASCRS members-2001 survey. J Cataract Refract Surg 2002;28:1681-8.

3 Caroll FD. Optic nerve compressions of cataract extraction. Trans Am Acad Ophthalmol Otolaryngol 1973;77:623-9.

4 Hayreh SS. Anterior ischemic optic neuropathy. IV. Occurrence after cataract extraction. Arch Ophthalmol 1980;98:1410-6.

5 Ruprecht KW, Naumann GOH. Uni- und bilaterale ischämische Papilleninfarkte nach Katarakt-Extraktion. Fortschr Ophthalmol 1985;82:349-352.

6 Klein ML, Jampol LM, Condon Pl, et al. Central retinal artery occlusion without retrobulbar hemorrhage after retrobulbar anesthesia. Am J Ophthalmol 1982:93:573-7.

7 Gass JD, Parrish R. Outer retinal ischemic infarction-a newly recognized complication of cataract extraction and closed vitrectomy. Part 1. A case report. Ophthalmology 1982;89:1467-71.

8 Parrish R, Gass JD, Anderson DR. Outer retina ischemic infarction--a newly recognized complication of cataract extraction and closed vitrectomy. Part 2. An animal model. Ophthalmology 1982;89:1472-7.

9 Hulbert MF, Yang YC, Pennefather PM, et al. Pulsatile ocular blood flow and intraocular pressure during retrobulbar injection of lignocaine: influence of additives. J Glaucoma 1998;7:413-16.

10 Coupland SG, Deschenes MC, Hamilton RC. Impairment of ocular blood flow during regional orbital anesthesia. Can J Ophthalmol 2001;36:140-4. 
11 Netland PA Siegner SW Harris. A. Color Doppler ultrasound measurements after topical and retrobulbar epinephrine in primate eyes. Invest Ophthalmol Vis Sci 1997;38:2655-61

12 Plange N, Remky A, Arend O. Colour Doppler imaging and fluorescein filling defects of the optic disc in normal tension glaucoma. $\mathrm{Br} J$ Ophthalmol 2003;87:731-6.

13 Williamson TH, Harris A. Color Doppler ultrasound imaging of the eye and orbit. Surv Ophthalmol 1996;40:255-67.

14 Harris A, Spaeth G, Wilson R, et al. Nocturnal ophthalmic arterial hemodynamics in primary open-angle glaucoma. J Glaucoma 1997;6:170-4.

15 Evans DW, Harris A, Garrett M, et al. Glaucoma patients demonstrate faulty autoregulation of ocular blood flow during posture change. $\mathrm{Br} J$ Ophthalmol 1999:83:809-13.

16 Lieb WE. Color Doppler imaging of the eye and orbit. Radiol Clin North Am 1998;36: 1059-71.

17 Harris A, Williamson TH, Martin B, et al. Test/retest reproducibility of color Doppler imaging assessment of blood flow velocity in orbital vessels. J Glaucoma 1995:4:281-6.

18 Shammas HJ, Milkie M, Yeo R. Topical and subconjunctival anesthesia for phacoemulsification: prospective study. J Cataract Refract Surg 1997;23:1577-80.
19 Vicary D, McLennan S, Sun XY. Topical plus subconjunctival anesthesia for phacotrabeculectomy: one year follow-up. J Cataract Refract Surg 1998;24:1247-51.

20 Schlote T, Derse M. Subconjunctival anesthesia in contact diode laser cyclophotocoagulation. Ophthalmic Surg Lasers 2001;32:289-93.

21 Chang BY, Hee WC, Ling R, et al. Local anaesthetic techniques and pulsatile ocular blood flow. Br J Ophthalmol 2000;84:1260-3.

22 Hessemer V, Wieth K, Heinrich A, et al. Changes in uveal and retinal hemodynamics caused by retrobulbar anesthesia using various injection volumes. Fortschr Ophthalmol 1989:86:760-6.

23 Meyer D, Hamilton RC, Loken RG, et al. Effect of combined peribulbar and retrobulbar injection of large volumes of anesthetic agents on the intraocular pressure. Can J Ophthalmol 1992;27:230-2.

24 Meyer P, Flammer J, Luscher TF. Local anesthetic drugs reduce endotheliumdependent relaxations of porcine ciliary arteries. Invest Ophthalmol Vis Sci 1993;34:2730-6.

25 Schaffer J, Biscoping J, Werry $\mathrm{H}$, et al. Local anesthetic level and cardiovascular changes following local anesthesia in cataract operations with 3\% mepivacaine. Fortschr Ophthalmol 1989:86:319-22

26 Bellucci R, Morselli S, Pucci V, et al. Intraocular penetration of topical lidocaine 4\%. J Cataract Refract Surg 1999;25:642-7. 